\title{
Almitrine and NO in acute respiratory distress syndrome: two pieces of the same puzzle?
}

\author{
L. Puybasset, J-J. Rouby
}

In the present issue of the European Respiratory Journal, PAPAZIAN et al. [1] demonstrate that the intravenous administration of almitrine together with the inhalation of a low dose of NO (10 parts per million (ppm)) to 41 patients with acute respiratory distress syndrome (ARDS) results in a dramatic improvement in arterial oxygenation: as a mean, a $100 \%$ increase in oxygen tension in arterial blood $\left(\mathrm{Pa}, \mathrm{O}_{2} /\right.$ inspiratory oxygen fraction $\left(\mathrm{FI}, \mathrm{O}_{2}\right)$ ratio was observed when both therapies were combined. This impressive result confirms seven previously published studies [2-8] demonstrating that the combination of intravenous almitrine and inhaled NO is very effective for improving arterial oxygenation at the early phase of ARDS.

By different mechanisms, both drugs improve $\mathrm{Pa}, \mathrm{O}_{2}$ by redistributing pulmonary blood flow from nonventilated towards ventilated lung areas. Inhaled NO relieves the constriction of pulmonary vessels perfusing normally- and poorly aerated lung areas. In ARDS, where nonventilated lung areas predominate over poorly-ventilated lung areas, $\mathrm{Pa}, \mathrm{O}_{2}$ increases whereas pulmonary artery pressure decreases $[7,9]$. In chronic obstructive pulmonary disease (COPD), where poorly-aerated lung areas predominate over nonventilated lung areas, pulmonary artery pressure and $\mathrm{Pa}, \mathrm{O}_{2}$ may both decrease because NO reverses hypoxic pulmonary vasoconstriction and increases pulmonary blood flow towards low ventilation/perfusion ratio $\left(V^{\prime} / Q^{\prime}\right)$ regions [10]. Almitrine is a selective pulmonary vasoconstrictor that at doses $<5 \mu \mathrm{g} \cdot \mathrm{kg}^{-1} \cdot \mathrm{min}^{-1}$ reinforces hypoxic pulmonary vasoconstriction in poorly- and non-ventilated lung regions. The resulting effect is a redistribution of pulmonary blood flow towards normally-ventilated lung regions leading to a decrease in pulmonary shunt and an increase in arterial oxygenation.

True pulmonary shunt and low $\left(V^{\prime} / Q^{\prime}\right)$ regions are coexisting in the lungs of patients with ARDS and inhaled $\mathrm{NO}$ may have its beneficial effect on $\mathrm{Pa}_{\mathrm{a}} \mathrm{O}_{2}$ limited by the existence of poorly-ventilated lung regions in which it deteriorates regional oxygenation by inhibiting hypoxic pulmonary vasoconstriction. Almitrine could specifically meet this limitation by locally re-establishing some degree of vasoconstriction. As a matter of fact, there is a strong rationale for combining almitrine and $\mathrm{NO}$ and it is not surprising that all human studies performed in patients with ARDS found that NO and almitrine add their effects for improving arterial oxygenation.

Correspondence: L. Puybasset, Praticien Hospitalier, Réanimation Chirurgicale Pierre Viars, Dépt d'Anesthésie-Réanimation, Hôpital PitiéSalpétrière, Université Pierre et Marie Curie Paris VI, Paris, France. Fax: 33142162269.
One interesting result of the study by PAPAZIAN et al. [1] is the lack of response to almitrine in patients receiving intravenous noradrenalin for septic shock. This contrasts with the results of GALLART et al. [7] who found that patients with septic shock receiving noradrenalin respond to almitrine by an increase in $\mathrm{Pa}, \mathrm{O}_{2}$ of the same magnitude as the one observed in patients without septic shock. In addition, GALLART et al. [7] also found that a lower dose of almitrine is required in patients receiving noradrenalin for obtaining the plateau effect on arterial oxygenation (2 versus $\left.4 \mu \mathrm{g} \cdot \mathrm{kg}^{-1} \cdot \mathrm{min}^{-1}\right)$. Why these conflicting results? The explanation probably resides in the differences in the basal pulmonary artery pressure measured in the patients of each study: in the study by PAPAZIAN et al. [1], the mean pulmonary artery pressure of patients receiving noradrenalin was $24 \pm 1 \mathrm{mmHg}$ (mean \pm SEM) before almitrine administration whereas it was $22 \pm 3 \mathrm{mmHg}$ in the patients of the study by GaLLARTs et al. [7]. Since pulmonary vascular resistance was increased in the same proportion in the two studies $\left(5.6 \mathrm{U} \cdot \mathrm{m}^{-2}\right)$, pulmonary blood flow was much higher in the patients from the study by PAPAZIAN et al. [1]. It can therefore be suspected that almitrine-induced vasoconstriction is inhibited by the presence of a high pulmonary blood flow. Further studies are required to confirm this hypothesis.

Almitrine is available in France for patients with COPD and is increasingly used in intensive care units to reverse severe hypoxaemia resulting from ARDS. Doses around 4 $\mu \mathrm{g} \cdot \mathrm{kg}^{-1} \cdot \mathrm{min}^{-1}$ and ranging $1-16 \mu \mathrm{g} \cdot \mathrm{kg}^{-1} \cdot \mathrm{min}^{-1}$ are administered for periods of 2-3 days at the early phase of ARDS. The pharmacological tolerance seems to be good: several hundred critically ill patients have been treated and only a few side effects have been reported $[5,11]$. However, three potential issues concerning almitrine's toxicity should be outlined. At doses $>5 \mu \mathrm{g} \cdot \mathrm{kg}^{-1} \cdot \mathrm{min}^{-1}$, almitrine constricts the entire pulmonary circulation [12] and induces a significant rise in pulmonary artery pressure that represents an increased afterload for the right ventricle [1-9]. Gallart et al. [7] have demonstrated that in patients with ARDS, four-fold lower doses allow the same improvement in arterial oxygenation without inducing a marked rise in pulmonary artery pressure. As a consequence, the doses that can be recommended today are between 2 and $4 \mu \mathrm{g} \cdot \mathrm{kg}^{-1} \cdot \mathrm{min}^{-1}$ and are not usually associated with a marked rise in pulmonary artery pressure. Another potential issue is the neurological toxicity of almitrine. Polyneuropathies associated with long term almitrine administration to patients with COPD (100-200 $\mathrm{mg} \cdot \mathrm{day}^{-1}$ for several months) were reported in the mid 1980s [12, 13]. A prospective randomized study has 
shown that neurological toxicity can be prevented by halving the daily dose $\left(5-100 \mathrm{mg} \cdot \mathrm{day}^{-1}\right.$ for period as long as 9 months) [14]. In critically ill patients, there is no published study reporting peripheral neuropathy following the administration of almitrine at the early phase of ARDS. However, it may be difficult to distinguish polyneuropathies related to sepsis, muscle relaxants, corticosteroids and almitrine. A last issue concerning the toxicity of almitrine is its potential for inducing lactate accumulation. $\mathrm{B}^{\prime} \mathrm{CHIR}$ et al. [5] have reported in 25 patients with focal lung lesions and receiving almitrine in doses ranging 2-8 $\mu \mathrm{g} \cdot \mathrm{kg}^{-1} \cdot \mathrm{min}^{-1}$, a sub-group of $8 \mathrm{pa}-$ tients in whom a significant increase in plasma lactate was observed $24 \mathrm{~h}$ following the administration of the drug. In constrast, no increase in lactate concentrations was found by GALLART et al. [7] in 17 patients receiving almitrine at doses ranging $2-16 \mu \mathrm{g} \cdot \mathrm{kg}^{-1} \cdot \mathrm{min}^{-1}$. Unless additional studies comparing the change of plasma lactate between patients receiving and not receiving almitrine rule out the risk of lactate accumulation, daily monitoring of lactate concentration is recommended in patients with ARDS treated by almitrine. The drug should be interrupted if plasma lactate increases.

From the existing literature, the combination of inhaled NO and intravenous almitrine appears today as an attractive therapeutic option for reversing severe impairment of arterial oxygenation at the early phase of acute respiratory distress syndrome. Its long-term effects on arterial oxygenation, outcome and duration of mechanical ventilation are not known and remain to be evaluated by randomized multicentre studies.

\section{References}

1. Papazian L, Bregeon F, Gaillat F, et al. Inhaled nitric oxide and almitrine bismesylate in patients with acute respiratory distress syndrome: effect of norepinephrine. Eur Respir J 1999; 14: 1283-1289.

2. Wysocki M, Delclaux C, Roupie E, et al. Additive effect on gas exchange of inhaled nitric oxide and intravenous almitrine bismesylate in the adult respiratory distress syndrome. Intensive Care Med 1994; 20: 254-259.

3. Lu Q, Mourgeon E, Law-Koune JD, et al. Dose-response curves of inhaled nitric oxide with and without intravenous almitrine in nitric oxide-responding patients with ac- ute respiratory distress syndrome. Anesthesiology 1995; 83: 929-943.

4. Jolliet P, Bulpa P, Ritz M, Ricou B, Lopez J, Chevrolet JC. Additive beneficial effects of the prone position, nitric oxide, and almitrine bismesylate on gas exchange and oxygen transport in acute respiratory distress syndrome. Crit Care Med 1997; 25: 786-794.

5. B'Chir A, Mebazaa A, Losser MR, Romieu M, Payen D. Intravenous almitrine bismesylate reversibly induces lactic acidosis and hepatic dysfunction in patients with acute lung injury. Anesthesiology 1998; 89: 823-830.

6. Payen D, Muret J, Beloucif S, et al. Inhaled nitric oxide, almitrine infusion, or their coadministration as a treatment of severe hypoxemic focal lung lesions. Anesthesiology 1998; 89: 1157-1165.

7. Gallart L, Lu Q, Puybasset L, Umamaheswara Rao GS, Coriat $\mathrm{P}$, Rouby JJ. Intravenous almitrine combined with inhaled nitric oxide for acute respiratory distress syndrome. The NO Almitrine Study Group. Am J Respir Crit Care Med 1998; 158: 1770-1777.

8. Gillart T, Bazin JE, Cosserant B, et al. Combined nitric oxide inhalation, prone positioning and almitrine infusion improve oxygenation in severe ARDS. Can J Anaesth 1998; 45: 402-409.

9. Reyes A, Roca J, Rodriguez-Roisin R, Torres A, Ussetti $\mathrm{P}$, Wagner PD. Effect of almitrine on ventilation-perfusion distribution in adult respiratory distress syndrome. $\mathrm{Am}$ Rev Respir Dis 1988; 137: 1062-1067.

10. Blanch L, Joseph D, Fernandez R, et al. Hemodynamic and gas exchange responses to inhalation of nitric oxide in patients with the acute respiratory distress syndrome and in hypoxemic patients with chronic obstructive pulmonary disease. Intensive Care Med 1997; 23: 51-57.

11. Sicsic JC, Jugan E, Moine P, Edouard A, Samli K. Reversible hepatic cytolysis during almitrine bismesylate treatment for posttraumatic ARDS. Intensive Care Med 1996; 22: 173-174.

12. Gherardi R, Louarn F, Benvenuti C, et al. Peripheral neuropathy in patients treated with almitrine dimesylate. Lancet 1985; 1: 1247-1250.

13. Bardsley PA, Howard P, DeBacker W, et al. Two years treatment with almitrine bismesylate in patients with hypoxic chronic obstructive airways disease. Eur Respir $J$ 1991; 4: 308-310.

14. Bardsley PA, Howard P, Tang O, et al. Sequential treatment with low dose almitrine bismesylate in hypoxaemic chronic obstructive airways disease. Eur Respir J 1992; 5: 1054-1061. 